\title{
Coluche : l'histoire d'un mec qui est mort il y a 30 ans
}

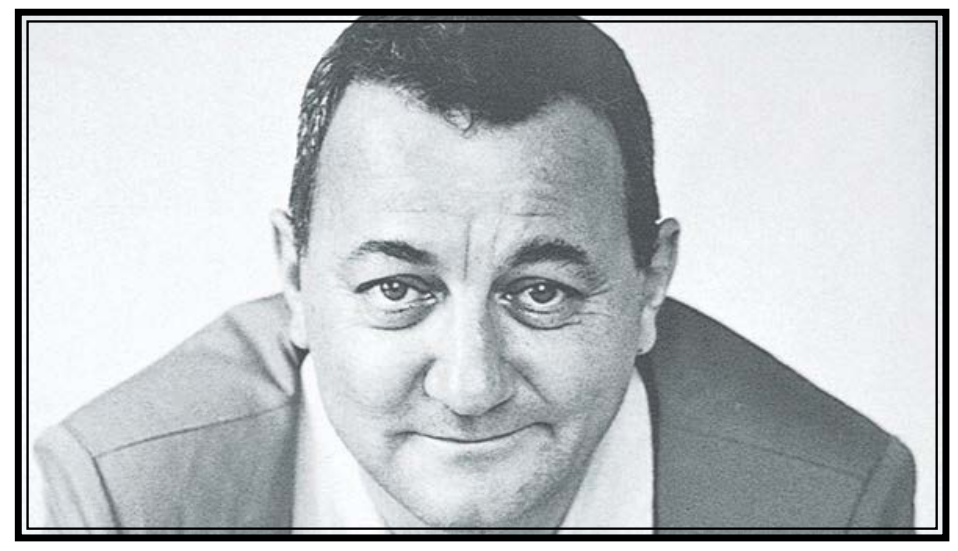

«Le plus dur pour les hommes politiques, c'est d'avoir la mémoire qu'il faut pour se souvenir de ce qu'il ne faut pas dire».

[...] le 19 juin 1986, Coluche nous quittait dans un tragique accident de moto.

Il avait 41 ans.

Coluche, de son vrai nom Michel COLUCCI, est né à Montrouge le 28 octobre 1944.

Orphelin de père, les études ne le passionnent pas et il ne possède que son certificat d'études primaires qu'il obtient en 1958.

Il commença à travailler dès l'âge de quinze ans et multiplia les petits boulots (Garçon de café, livreur...) puis Coluche rencontra la bande du «le Café de la gare», troupe créée par Romain Bouteille en 1969 où il joua notamment aux côtés de Patrick Dewaere, Henri Guybet, Miou-Miou, Gérard Depardieu, Thierry Lhermitte, Josiane Balasko et Gérard Jugnot.

Son premier sketch C'est l'histoire d'un mec tourne en dérision la difficulté de raconter une histoire. Très vite, les sketches suivants lui vaudront un véritable succès populaire.

Il revendique sa grossièreté : " Toujours grossier, jamais vulgaire ». En novembre 1971, il crée sa propre troupe $A u$ vrai chic parisien Théâtre vulgaire, puis Le vrai chic parisien.
Son premier spectacle s'intitule Thérèse est triste.

Du 15 février au 2 mars 1974, Coluche est à l'Olympia pour son spectacle Mes adieux au music-hall. Sa célèbre salopette à rayures bleues et son tee-shirt jaune font leur apparition à ce moment.

Coluche fait également une apparition à la télévision le 19 mai 1974 avec L'histoire d'un mec. Son sketch apparaît entre l'intervention entre les deux tours de la Présidentielle de 1974 entre Valéry Giscard d'Estaing et François Mitterrand.

D'avril 1974 à juin 1979, il coanime l'émission On n'est pas là pour se faire engueuler sur Europe 1.

Plus qu'un homme qui veut faire rire, Coluche veut faire bouger les choses.

Ainsi le 15 juin 1985, il anime avec Guy Bedos le concert de SOS Racisme place de la Concorde.

Et il organise le 25 septembre 1985 un gigantesque canular : les télévisions et la France entière peuvent assister au mariage de Coluche et de Thierry Le Luron, "pour le meilleur et pour le rire». 
Une provocation avant-gardiste autour $\mathrm{du}$ mariage homosexuel et une parodie du très médiatisé mariage $d^{\prime} Y$ ves Mourousi, le présentateur TV vedette de l'époque.

De juillet 1985 à mars 1986, il anime l'émission Y'en aura pour tout le monde sur Europe 1 ainsi que Coluche 1 faux sur Canal + à la même période.

Coluche s'est aussi essayé au jeu de la politique puisqu'il avait lancé une campagne pour être candidat à l'élection présidentielle de 1981.

Il annonça sa candidature le 30 octobre 1980. Le 14 décembre, un sondage publié par le Journal du dimanche le crédite de $16 \%$ des intentions de vote.

Il se retira de la course le 15 mars de l'année suivante, selon lui à cause des pressions politiques.

Issu d'un milieu défavorisé, "Je ne suis pas un nouveau riche, je suis un ancien pauvre», il a pris conscience de grosses défaillances dans l'entraide française envers les plus démunis et a créé les Restos du Cœur (www.restosducoeur. org/ ) en 1985.

Il lança l'idée des restos sur Europe 1 le 26 septembre 1985 en déclarant : "J'ai une petite idée comme ça, si des fois y'a des marques qui m'entendent, je ferai un peu de pub tous les jours. Si y'a des gens qui sont intéressés pour sponsorer [sic] une cantine gratuite qu'on pourrait commencer par faire à Paris».

Il est également à l'origine de la loi Coluche, votée en 1988, qui permet à un donateur de déduire une partie de son don de ses impôts.

Sa célèbre salopette lui avait été donnée par le mouvement Emmaüs. Devenu célèbre, il renvoya l'ascenseur en remettant un chèque d'un montant élevé à l'abbé Pierre pour ce mouvement.
Passionné de sports mécaniques, il s'est engagé sur le Paris-Dakar. Il a aussi tenté et obtenu le record du monde de vitesse du kilomètre lancé sur piste à moto, le 29 septembre 1985.

Coluche décéda tragiquement [...] le 19 juin 1986 à l'âge de 41 ans d'un accident de moto, percutant un camion effectuant une manœuvre délicate.

Le chanteur Renaud, grand ami de Coluche (qui était le parrain de sa fille Lolita), lui dédia une chanson quelques jours seulement après sa mort : Putain de camion.

Coluche est enterré au cimetière de Montrouge, dans le $14 \mathrm{e}$ arrondissement parisien, près de la porte d'Orléans.

Tour à tour admiré, craint, dénigré, Coluche s'est posé comme le provocateur des années 1980, osant la grossièreté, et chacune de ses apparitions télévisées était attendue avec grand plaisir. Il a su donner un nouveau visage à la télévision.

Il avait le sens du rire et de la dérision, avec lui tout y passait : au-delà des différences et des clivages politiques, sociaux, culturels, Coluche avait toujours son mot à dire sur tout mais tout en étant caustique, il savait rester correct, poli et respectueux.

Il savait dénoncer, sans pour autant être méchant, il savait se montrer incisif sans blesser.

30 ans après, son humour, ses mots et sa générosité lui survivent et il est encore un comique apprécié.

http://arnaudmouillard.fr/2016/06/19/ coluche-lhistoire-dun-mec-qui-est-mort-il-y-a30-ans/ 